\title{
Loss Prediction and Thermal Analysis of Surface-Mounted Brushless AC PM Machines for Electric Vehicle Application Considering Driving Duty Cycle
}

\author{
Tianxun Chen, ${ }^{1}$ Xiaopeng Wu, ${ }^{2}$ Yugang Dong, ${ }^{2}$ Chengning Zhang, ${ }^{2}$ and Haipeng Liu ${ }^{2}$ \\ ${ }^{1}$ Jinhua Polytechnic, Zhejiang 321007, China \\ ${ }^{2}$ Beijing Institute of Technology, Beijing 100081, China \\ Correspondence should be addressed to Xiaopeng Wu; xiaopengwu@hotmail.com
}

Received 11 May 2015; Revised 21 June 2015; Accepted 5 July 2015

Academic Editor: Xiaosong Hu

Copyright ( $\odot 2016$ Tianxun Chen et al. This is an open access article distributed under the Creative Commons Attribution License, which permits unrestricted use, distribution, and reproduction in any medium, provided the original work is properly cited.

\begin{abstract}
This paper presents a computationally efficient loss prediction procedure and thermal analysis of surface-mounted brushless AC permanent magnet (PM) machine considering the UDDS driving duty cycle by using a lumped parameters' thermal model. The accurate prediction of loss and its variation with load are essential for thermal analysis. Employing finite element analysis (FEA) to determine loss at every load point would be computationally intensive. Here, the finite element analysis and/or experiment based computationally efficient winding copper and iron loss and permanent magnet (PM) power loss models are employed to calculate the electromagnetic loss at every operation point, respectively. Then, the lumped parameter thermal method is used to analyse the thermal behaviour of the driving PM machine. Experiments have been carried out to measure the temperature distribution in a motor prototype. The calculation and experiment results are compared and discussed.
\end{abstract}

\section{Introduction}

The massive application of electric vehicle (EV) is a significant way to reduce the emission and to settle the energy crisis [1]. In general, the types of EVs can be categorized as pure electric vehicle (PEV), hybrid electric vehicle (HEV), and fuel cell electric vehicle (FCEV) [1-3]. To all these subcategories, electric machine is always the key traction component, which needs to be well designed and manufactured.

Among all the types of electric machine, brushless AC PM machine is a promising candidate for EV traction motor due to its high power density, high efficiency, fast dynamics, and compactness $[4,5]$. However, this kind of machine could easily suffer insulation failure of coils and irreversible demagnetization due to the poor cooling condition on the rotor side and excessive heat generation on the stator side, especially for variable-speed application [6]. Therefore, the accurate temperature prediction for traction brushless AC PM machine is of great importance at the design stage.

In fact, one of the key elements of accurate thermal analysis is the accurate losses calculation. Generally, there are two main sources of loss within an electric machine: mechanical and electromagnetic. Mechanical loss is attributed to the frictional effects within the bearing assembly (bearing loss) and fluid dynamics or aerodynamics effects within the motor body (windage or drag loss) [7]; it can be easily obtained according to the manufacturer's manual. Electromagnetic losses, which effect thermal analysis heavily, are usually associated with active parts of the motor assembly and include the iron, winding, and permanent magnet (PM) loss components [8-10].

For electromagnetic losses prediction, two approaches are widely used: analytical and numerical [11-19]. The analytical approach for iron loss calculation was first developed by Steinmetz [11] and then further modified by Bertotti [12]. The Bertotti formulation which divides the iron loss into three individual parts, that is, eddy current loss, hysteresis loss, and supplementary loss, is commonly used at current electric machine design stage. The analytical winding loss approaches have been well developed to account for the AC effect, for example, the skin effect and the proximity effect [13-15]. The AC equivalent resistance is the commonly used 
element to account for the AC effect. However, it is frequency dependent and would change with the change of operation point. Therefore, it would be difficult to calculate the winding losses of all operation points accurately by a single value of AC equivalent resistance. For PM power loss, a variety of analytical techniques have been developed. These are based on simplified assumptions of the field distribution and their use is limited to the selected machine topologies for which the assumptions hold [16, 17].

The numerical approach including time-stepping or frequency domain FEA is a more accurate way to calculate the electromagnetic losses $[4,18,19]$. However, it is time consuming and computationally intensive. Therefore, the numerical approach would not be suitable in the case that a loss map or an efficiency map is required.

Besides the losses prediction approaches, the thermal model is another important element for thermal analysis. Two main models could be found from literatures: FE based thermal model and lumped parameter thermal model [20, 21]. The FE based thermal model is accurate and capable of predicting the hottest pot within a motor, while it is time consuming. The lumped parameter thermal model is quick, while it could be only capable of calculating the mean temperature of each motor component. Thus, the choice of thermal model strongly depends on the design goals.

In addition, there has been increased interest in predicting temperature distribution under the driving duty cycle [4, 22]. A lumped parameter thermal model [20] has been used to calculate the temperature distribution under the Chinese city driving duty cycle in [4]. Good agreement is visible between the analytical and experimental results. However, the procedure presented is time consuming, since the FEA is employed to calculate the loss at each operating point. Some accurate and computationally efficient loss scaling techniques [23-25] have been presented, and some of them have been introduced into the analysis procedure and the equivalentcircuit lumped parameter thermal model has been adopted in the literature [22], while it does not take the PM loss into account, which may be small but can directly heat up magnets.

This paper proposes a computationally efficient loss prediction procedure and a lumped parameter thermal analysis of surface-mounted brushless AC PM machine considering the UDDS driving duty cycle. The machine is applied on a 10meter motor-direct-driving large coach bus. The FEA based iron loss [23], copper loss [24], and PM loss [25] scaling techniques are utilized to obtain the loss distribution under the driving duty cycle in a timely manner. The equivalent thermal parameter of winding [26] is calculated and introduced into the thermal model. Finally, the temperature of winding, stator, and PM is predicted and is compared with the results from experiment.

The remainder of the paper is organised in the following manner: Section 2 outlines the machine design exemplar and the selected coach bus configuration; Section 3 describes the analysis procedure and the electromagnetic loss scaling technique; Section 4 details thermal modelling; Section 5 describes the experimental setup and results; Section 6 summarizes the research findings.
TABLE 1: Selected details of driving motor.

\begin{tabular}{lc}
\hline Number of poles & 8 \\
Number of slots & 48 \\
Rated torque & $928 \mathrm{Nm}$ \\
Rated power & $350 \mathrm{~kW}$ \\
Motor outer diameter & $480 \mathrm{~mm}$ \\
Active length & $210 \mathrm{~mm}$ \\
\hline
\end{tabular}

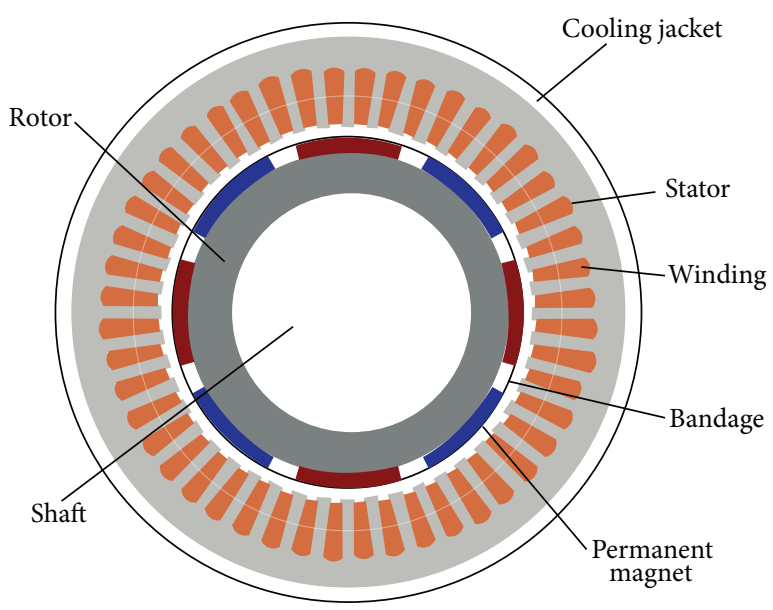

FIGURE 1: Geometry of analysed PM machine.

\section{Study Machine and Bus Model}

The analysed motor is a radial-flux, integer-slot, distributedwound internal-rotor PM machine with water cooling jacket, as shown in Figure 1. Selected details of the driving motor are given in Table 1. And basic traction parameters of selected coach bus are given in Table 2. Please note that the aim of this paper is to accelerate the analysis speed by using computationally efficient loss mapping techniques. Therefore, some of the coach bus traction parameters have been modified to ensure that torque-speed characteristic of analyzed machine can cover the torque-speed requirement.

\section{Analysis Procedure}

3.1. Outline of Analysis. In order to predict dynamic temperature distribution of the driving motor under the driving duty cycle, an analysis procedure is developed and shown in Figure 2.

The limited number of FEAs is utilized in order to derive the loss functions, which give access to loss predictions over the entire torque-speed envelope quickly. Meanwhile, the UDDS, shown in Figure 3, of EV is adopted. This duty cycle contains 1370 points and each point runs one second. The corresponding operating points of the driving motor including speed and torque are obtained. Then, by the computational loss derivations, the losses at each operating point can be easily achieved. Based on the loss predictions, the dynamic temperature distribution under the driving duty cycle is predicted by using lumped parameter thermal model. 
TABLE 2: Traction parameters of coach bus.

Gross vehicle weight $m$

Final drive ratio $i_{0}$

Frontal area $A$

Wheel radius $R_{r}$

Drivetrain efficiency $\eta$

Rolling resistance coefficient $\mu$

Aerodynamic drag coefficient $C_{D}$

Vehicle rotary mass coefficient $\sigma$

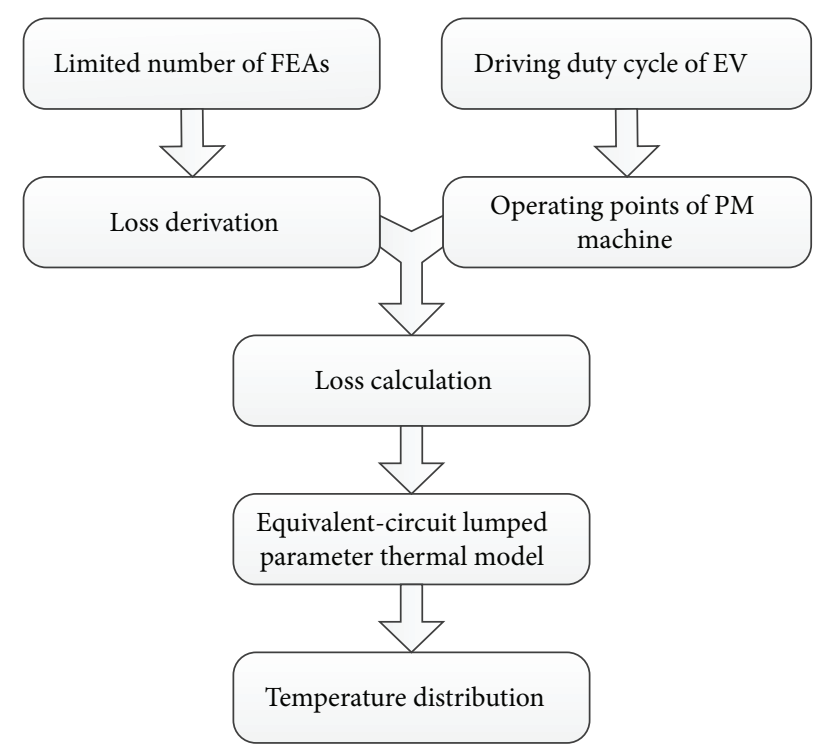

FIGURE 2: Outlines of analysis procedure.

3.2. Motor Torque and Speed Calculation. The corresponding operating points of the driving motor including speed and torque are derived from the following equation:

$$
n=\frac{v i_{0}}{0.377 R_{r}}
$$

Here, the unit of $v$ is $\mathrm{km} / \mathrm{h}$, so the vehicle speed in UUDs should be converted to $\mathrm{km} / \mathrm{h}$ by multiplying 1.61 :

$$
T=\frac{\left(\mu m g+C_{D} A v^{2} / 21.15+\sigma m a\right) R_{r}}{\left(i_{0} \eta\right)} .
$$

The machine torque map under UDDs duty cycle is shown on Figure 4. Here, the generator mode of analysed machine is ignored.

\subsection{Loss Derivation}

3.3.1. Iron Loss. The total iron loss occurring in the stator can be viewed as a superposition of two components. One stems from the main magnetizing flux path which flows through the teeth and back iron and couples the coils forming the stator winding. The other occurs during field weakening and is

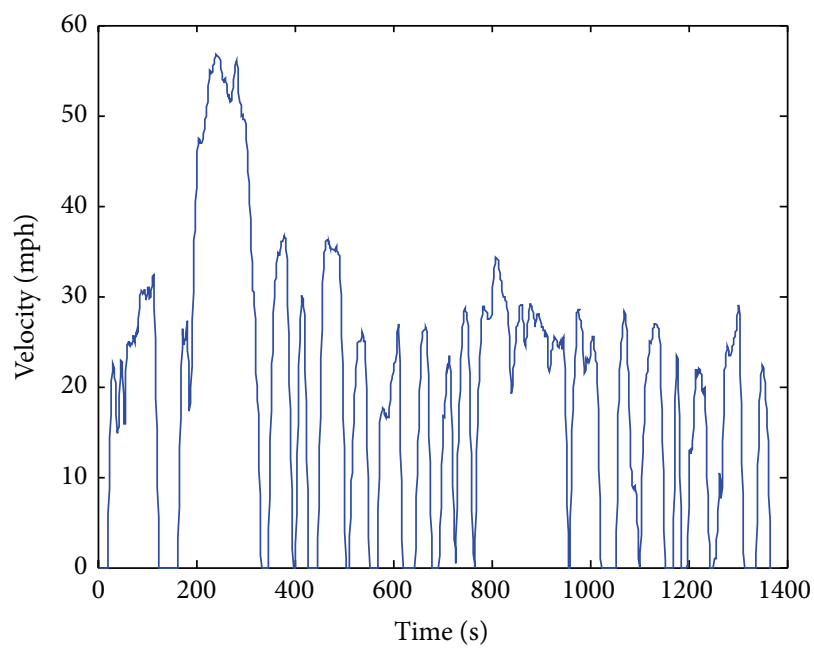

FIgURE 3: The UDDS driving duty cycle.

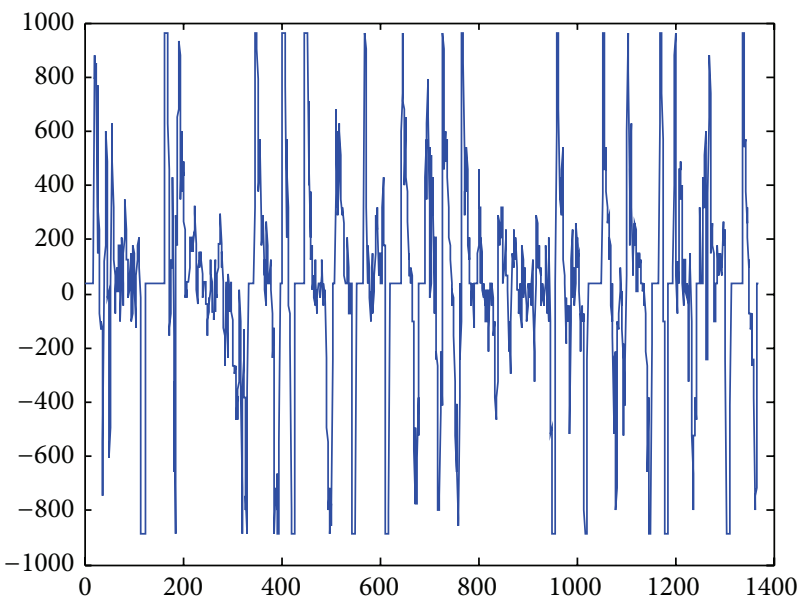

FIGURE 4: Torque requirement of UDDs duty cycle.

a result of flux emanating from the permanent magnets which flows across the face of the tooth tip and does not couple the stator coils [23]:

$$
P_{\text {iron }}=P_{1}+P_{2}
$$

where

$$
\begin{aligned}
& P_{1}=\frac{a_{h}}{\lambda} V_{m}+\frac{a_{J}}{\lambda^{2}} V_{m}^{2}+\frac{a_{\mathrm{ex}}}{\lambda^{1.5}} V_{m}^{1.5}, \\
& P_{2}=\frac{b_{h}}{\lambda} V_{d}+\frac{b_{J}}{\lambda^{2}} V_{d}^{2}+\frac{b_{\mathrm{ex}}}{\lambda^{1.5}} V_{d}^{1.5} .
\end{aligned}
$$

The $V_{m}$ and $V_{d}$ used in (4) are determined from the phasor diagram of direct-quadrature $d$ - $q$ axes describing the brushless AC operation of the motor, where

$$
\begin{gathered}
\lambda=\frac{E_{\mathrm{ph}}}{f}, \\
I_{q}=\frac{T}{k_{T}},
\end{gathered}
$$




$$
\begin{aligned}
& V_{d}=\lambda f \frac{I_{d}}{I_{\mathrm{SC}}} \\
& V_{m}=\lambda f \sqrt{\left(1-\frac{I_{d}}{I_{\mathrm{SC}}}\right)^{2}+\left(\frac{I_{q}}{I_{\mathrm{SC}}}\right)^{2}} .
\end{aligned}
$$

Here, $E_{\mathrm{ph}}$ is the phase EMF, $T$ is the torque, $I_{d}$ and $I_{q}$ are the magnitudes of the demagnetizing direct axis and quadrature axis components of stator phase current, $k_{T}$ is the motor torque constant, and $I_{\mathrm{SC}}$ is the short-circuit current calculated from FE analysis. The coefficients $a_{h, j, \text { ex }}$ and $b_{h, j, \text { ex }}$ for the hysteresis, Joule eddy-current, and excess losses have been found from curve fitting (4) to the FE open-circuit and shortcircuit loss results across the operating frequency $f$. Note that the iron loss in rotor core is relatively small in this case, so it can be neglected.

3.3.2. Copper Loss. The electrical resistivity of copper increases with operating temperature elevating, which results in simultaneous rise of DC loss component and reduction of the AC loss component caused by skin, proximity, and other eddy current effects [24]. The overall copper power loss and its thermal variation at AC operation depend on the balance between these two loss components [22]. Here, the copper loss scaling approach proposed in [24] has been employed. The end-winding copper loss will be separated from the total copper loss by multiplying a ratio between endwinding length and total winding length.

$$
\begin{aligned}
\left.P_{\mathrm{AC}}\right|_{T}= & \left.I^{2} R_{\mathrm{DC}}\right|_{T_{0}} \frac{\left(R_{\mathrm{AC}} /\left.R_{\mathrm{DC}}\right|_{T_{0}}\right)-1}{\sqrt{\left(1+\alpha\left(T-T_{0}\right)\right)}} \\
& +\left.I^{2} R_{\mathrm{DC}}\right|_{T_{0}}\left(1+\alpha\left(T-T_{0}\right)\right),
\end{aligned}
$$

where $\alpha$ is the temperature coefficient of resistivity of copper, $3.93 e-3 \mathrm{~K}^{-1}$, and $\left.I^{2} R_{\mathrm{DC}}\right|_{T_{0}}$ is the DC copper loss at reference temperature $T_{0}$, which is set at $25^{\circ} \mathrm{C}$ in this case.

3.3.3. PM Loss. The eddy current loss generated in the magnet array stems from two effects. The first results from the permeance variation caused by stator slotting and the second from the armature reaction field. The complete functional representation of PM loss catering for both constant torque and constant power operating regions can be then written in the following form [25]:

$$
P_{\mathrm{PM}}=\left(a I_{q}^{2}+b I_{d}^{2}+c I_{d}+d\right)\left(\frac{n}{n_{W}}\right)^{2} .
$$

Here, the coefficients $a, b, c$, and $d$ can be derived from four individual FEAs accounting for open-circuit, rated current in the quadrature axis, rated current in the direct axis, and reduced current in the direct axis. And $n$ is the rotatory speed; $n_{W}$ is the reference speed which should be set within the field weakened regime of operation.

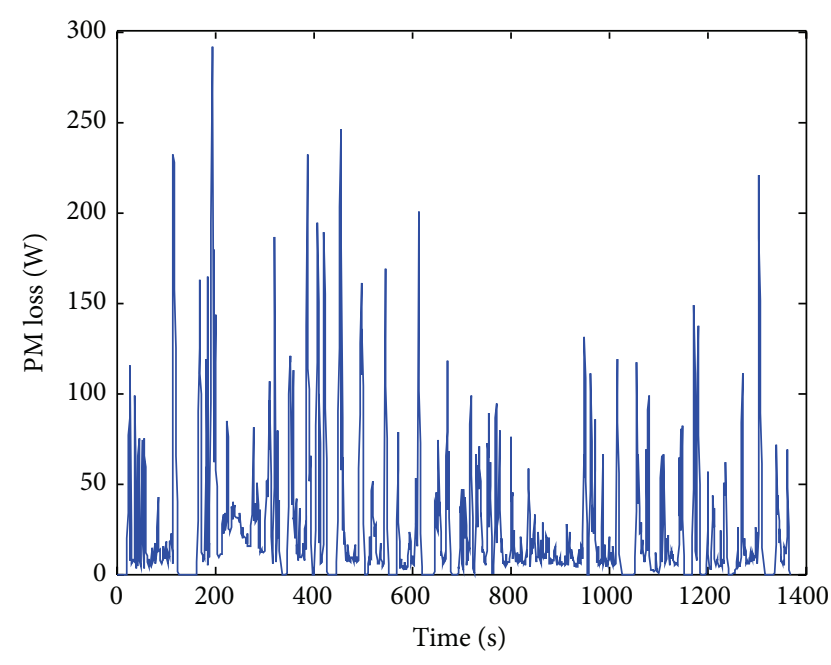

FIGURE 5: PM loss distribution under the UDDS driving duty cycle.

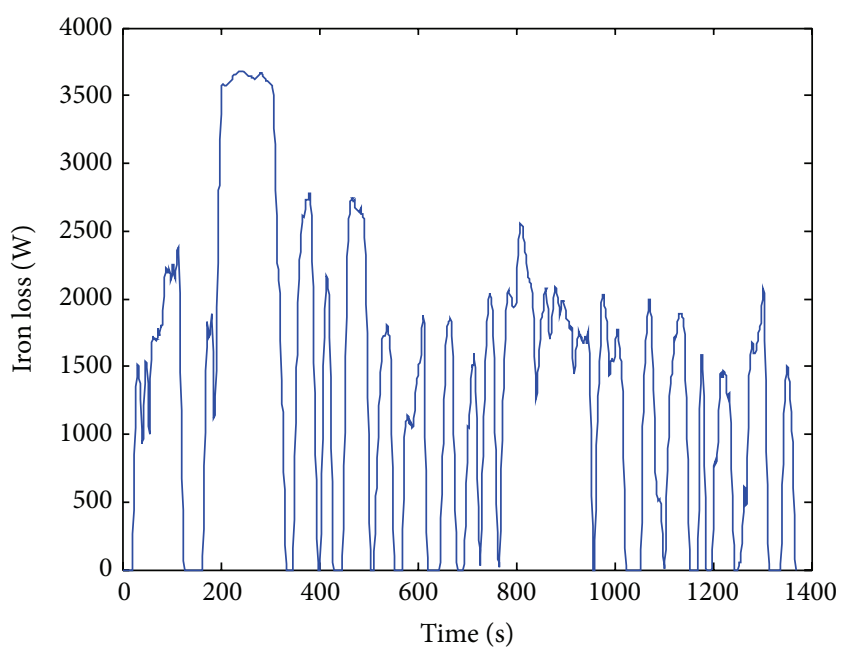

FIGURE 6: Iron loss distribution under the UDDS driving duty cycle.

3.3.4. Other Losses. The bearing and frictional loss is calculated according to the manufacturer's manual.

Figures 5 and 6 show the PM loss and iron loss distribution individually according to (3) and (7) in a single UDDS driving duty cycle. And the mechanical loss distribution is presented in Figure 7. Note that as the copper loss scaling technique requires transient temperature, the copper loss distribution remains unknown at this stage. However, the copper loss at ambient temperature $25^{\circ} \mathrm{C}$ is easily obtained and would be used as initial condition.

Table 3 illustrates the comparison between the technique proposed in [4] and the presented technique in the paper. As only 6 steps of FEA are utilised in the presented technique, the analysis time of complete duty cycle could be able to be reduced from 2 hours to just several minutes, compared to the previous technique where 1314 FEAs are adopted. In addition, the PM loss is further taken into account in the presented technique, which will result in a more accurate thermal analysis. By using all these means, the analysis time 
TABlE 3: Comparison between previous technique in [3] and proposed technique in this paper.

\begin{tabular}{lll}
\hline & Technique in [3] & $\begin{array}{l}\text { Proposed } \\
\text { technique }\end{array}$ \\
\hline $\begin{array}{l}\text { Numbers of FEA } \\
\begin{array}{l}\text { Analysis time of } \\
\text { compete duty cycle }\end{array}\end{array}$ & $\begin{array}{l}\text { More than 2 } \\
\text { hours }\end{array}$ & Around 5 min \\
\hline $\begin{array}{l}\text { Types of } \\
\text { electromagnetic loss }\end{array}$ & $\begin{array}{l}\text { Winding loss, } \\
\text { iron loss, and } \\
\text { mechanical loss }\end{array}$ & $\begin{array}{l}\text { Winding loss, } \\
\text { iron loss, PM loss, } \\
\text { and mechanical } \\
\text { loss }\end{array}$ \\
\hline
\end{tabular}

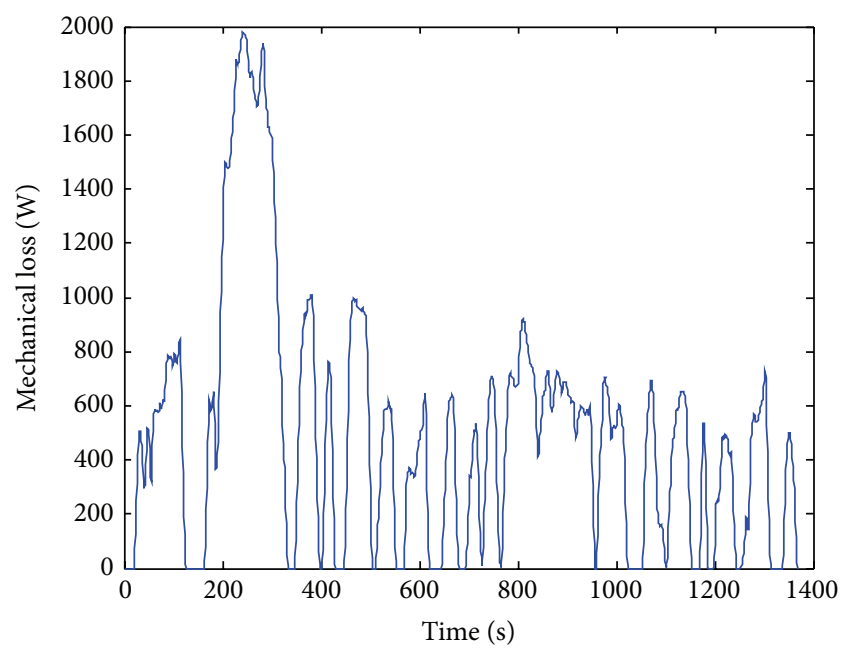

FIGURE 7: Mechanical loss distribution under the UDDS driving duty cycle.

could be reduced substantially, and the results could be more reliable.

\section{Thermal Analysis}

4.1. Calculation of Thermal Parameters. Figure 5 shows the general thermal network for component based on the assumption that temperature in the PM machine is axially symmetrical. Here, there are three unknown temperatures: the outer surface $T_{r, 1}$, the inner surface $T_{r, 2}$, and the axial edge $T_{a}$. And the four thermal resistances which constitute the network can be calculated by the following equations:

$$
\begin{aligned}
& R_{1}=\frac{1}{2 \pi k_{r} L}\left(1-\frac{2 r_{2}^{2} \ln \left(r_{1} / r_{2}\right)}{\left(r_{1}^{2}-r_{2}^{2}\right)}\right), \\
& R_{2}=\frac{1}{2 \pi k_{r} L}\left(\frac{2 r_{1}^{2} \ln \left(r_{1} / r_{2}\right)}{\left(r_{1}^{2}-r_{2}^{2}\right)}-1\right), \\
& R_{3}=\frac{L}{6 \pi k_{a}\left(r_{1}^{2}-r_{2}^{2}\right)}, \\
& R_{m}=\frac{-1}{4 \pi\left(r_{1}^{2}-r_{2}^{2}\right) k_{r} L}\left(r_{1}^{2}+r_{2}^{2}-\frac{4 r_{1}^{2} r_{2}^{2} \ln \left(r_{1} / r_{2}\right)}{\left(r_{1}^{2}-r_{2}^{2}\right)}\right),
\end{aligned}
$$

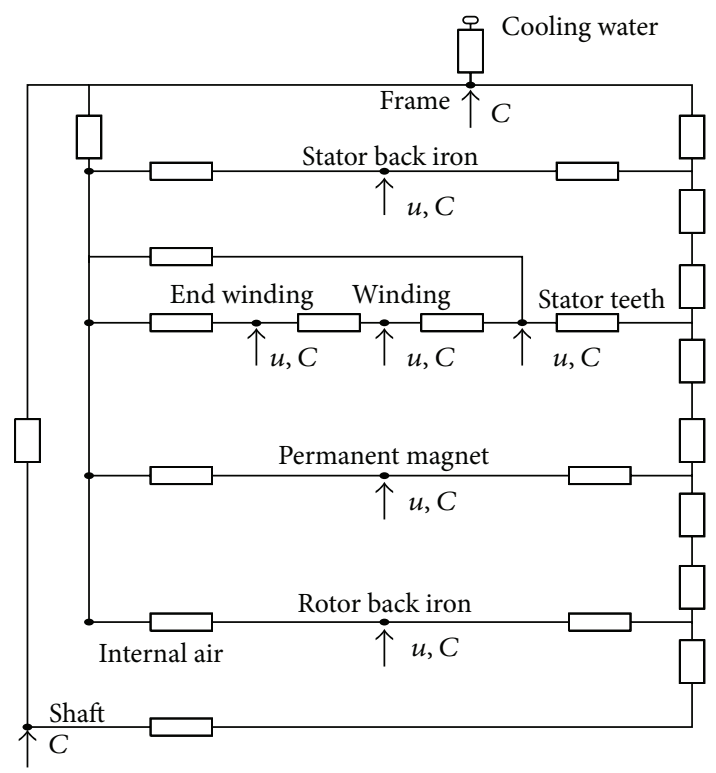

Figure 8: Lumped parameter thermal model. $C=$ thermal capacitance, $u=$ heat generation.

where $r_{1}$ and $r_{2}$ are the outer and inner radius of a general cylindrical component, respectively, and $k_{a}$ and $k_{r}$ are the axial and radial thermal conductivities of a general cylindrical component, respectively.

The lump parameter thermal model is shown in Figure 8, which contains nine key components of surface-mounted brushless AC PM machine. Based on the previous assumption, only half of the motor geometry is modelled. Also, it is assumed that heat flows in the radial and axial direction are independent and the heat generation is distributed inside the PM machine.

As a key component of surface-mounted brushless AC machine, the electrical winding is a heterogeneous material consisting of conductors, electrical insulation, impregnation insulation, and air and would easily suffer from severe thermal load condition. A full representation of the individual conductors and surrounding insulation system would add considerable complexity to a thermal model and leads to long solution times which limit the applicability of such models to both transient problems and iterative design/optimization procedures [26]. There are various modelling approaches to capture the thermal parameters of electrical winding [2730]. This paper uses the methodology presented in [26] to calculate the thermal conductivity and heat capacity:

$$
\begin{aligned}
v_{c}+v_{\mathrm{ci}} & =\mathrm{PF}, \\
v_{\mathrm{ii}} & =1-\mathrm{PF}, \\
v_{c} & =\mathrm{PF} \frac{r_{c}^{2}}{\left(r_{c}+l_{i}\right)^{2}}, \\
v_{\mathrm{ci}} & =\mathrm{PF} \frac{2 r_{c} l_{i}+l_{i}^{2}}{\left(r_{c}+l_{i}\right)^{2}},
\end{aligned}
$$




$$
\begin{aligned}
& k_{e}=k_{a} \frac{\left(1+v_{c}\right) k_{c}+\left(1-v_{c}\right) k_{a}}{\left(1-v_{c}\right) k_{c}+\left(1+v_{c}\right) k_{a}}, \\
& c_{e}=\frac{\operatorname{PF}\left(\rho_{c} c_{c}-\rho_{p} c_{p}\right)+\rho_{p} c_{p}}{\operatorname{PF}\left(\rho_{c}-\rho_{p}\right)+\rho_{p}},
\end{aligned}
$$

where $v_{c}, v_{\mathrm{ci}}$, and $v_{\mathrm{ii}}$ are the volume ratio of conductor, conductor insulation, and impregnation insulation, respectively. $\mathrm{PF}$ is the packing factor, $r_{c}$ is the conductor radius, and $l_{i}$ is the insulation thickness. $k_{e}$ and $k_{a}$ are the equivalent thermal conductivity of winding and insulation amalgam, respectively. $k_{c}$ is the thermal conductivity of conductor. $c_{e}$ is the equivalent heat capacity, and $c_{c}$ and $c_{p}$ are the heat capacity of conductor and impregnation compound. $\rho_{c}$ and $\rho_{p}$ are the density of conductor and impregnation compound.

The heat transfer coefficient of the fully developed turbulent flow in the spiral housing water jacket can be calculated according to [31]

$$
\begin{aligned}
h & =\frac{k_{f} N_{u}}{D_{h}}, \\
N_{u} & =\frac{(f / 8)\left(R_{e}-1000\right) P_{r}}{1+12.7(f / 8)^{2}\left(P_{r}^{2 / 3}-1\right)},
\end{aligned}
$$

where $N_{u}$ is the Nusselt number, $k_{f}$ is the thermal conductivity of fluid, and $D_{h}$ is the hydraulic diameter. $R_{e}=\rho v_{\mathrm{av}} D_{h} / \mu$ is the Reynolds number, $\rho$ is the fluid density, $v_{\mathrm{av}}$ is the fluid average velocity, $\mu$ is the fluid dynamic viscosity, $P_{r}$ is the Prandtl number, and $f$ is the friction factor for smooth cooling duct.

4.2. Transient State Thermal Model Equation. In order to predict the transient temperature distribution over the entire driving duty cycle, the dynamic thermal equation is utilized according to [31]

$$
\frac{d K_{i}}{d t}=\left[C_{t}\right]^{-1}\left[P_{t}\right]-\left[C_{t}\right]^{-1}\left(\left[G_{t}\right]+\left[G_{\text {fluid }}\right]\right)\left[K_{i}\right],
$$

where $C_{t}$ is the thermal capacitance matrix, $P_{t}$ is the heat loss matrix, $K_{i}$ is the temperature rise matrix, $G_{\text {fluid }}$ is the cooling fluid matrix, and $G_{t}$ is the thermal conductance matrix.

Figure 9 shows the copper distribution individually according to (6) in a single UDDS driving duty cycle. The temperature at every single operating point is used to derive the copper loss. And Figure 10 presents the temperature variations. The highest temperature appears in the stator end winding, which reaches to $93.3^{\circ} \mathrm{C}$. Over the entire driving duty cycle, the highest temperature of magnet, stator back iron, stator teeth, and winding is $41.3^{\circ} \mathrm{C}, 57.4^{\circ} \mathrm{C}, 59.1^{\circ} \mathrm{C}$, and $88.3^{\circ} \mathrm{C}$, respectively, and all of them come from the end of the duty cycle. In this analysis, the ambient temperature is set to $25^{\circ} \mathrm{C}$.

\section{Experimental Result}

The test bench used to measure the temperature of the motor prototype is shown in Figure 11. The temperature measuring

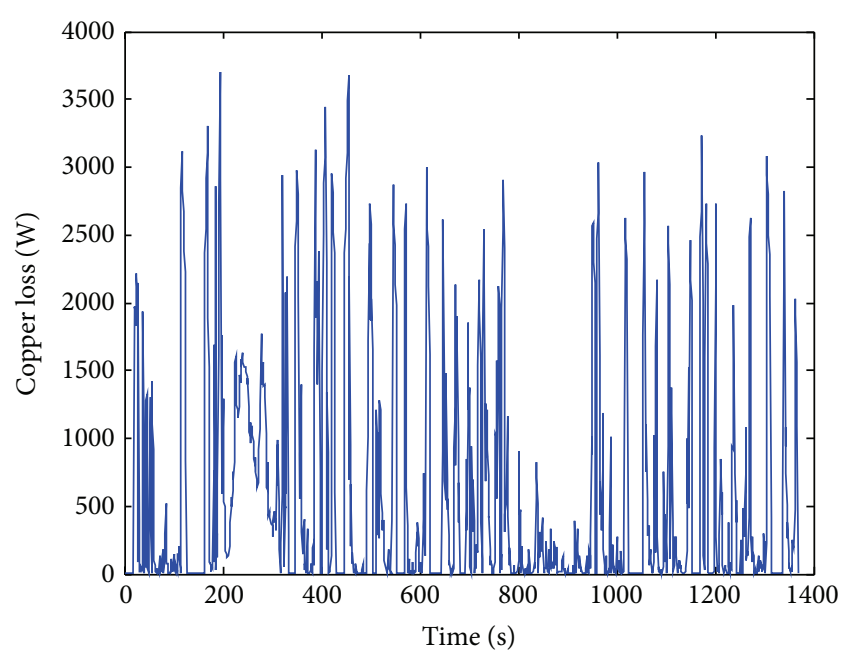

FIgURE 9: Copper loss distribution under the UDDS driving duty cycle.

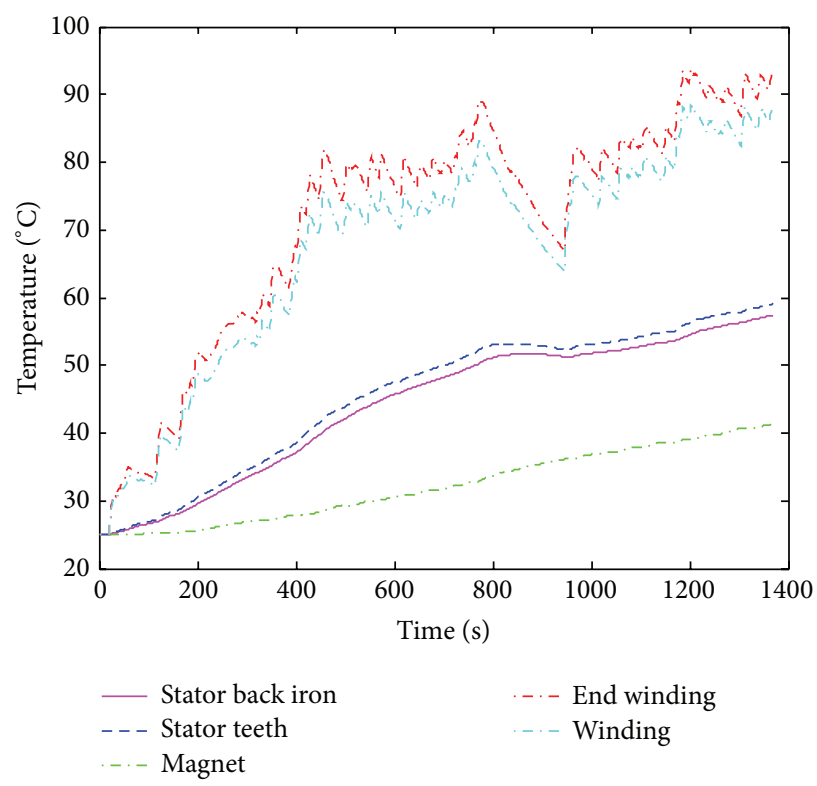

FIGURE 10: Dynamic temperature distribution under the UDDS driving duty cycle.

sensor PT1000 is placed in the end winding, since the end winding suffers from the most severe thermal condition. The ambient temperature is $25^{\circ} \mathrm{C}$ and the temperature difference between inlet and outlet is $2-3^{\circ} \mathrm{C}$.

Both the traction motor and generator are water-cooled and controlled by an integrated controller. The operation points of the traction motor are calculated through (1) and (2); each of them runs a single second. The end-winding temperature measured by the temperature sensor is manually recorded every 20 seconds.

The test and calculated results are shown in Figure 12. Good agreement in trend is visible, while the test results are relatively lower than those derived from calculation. It is important to note that the predicted temperature dropped 


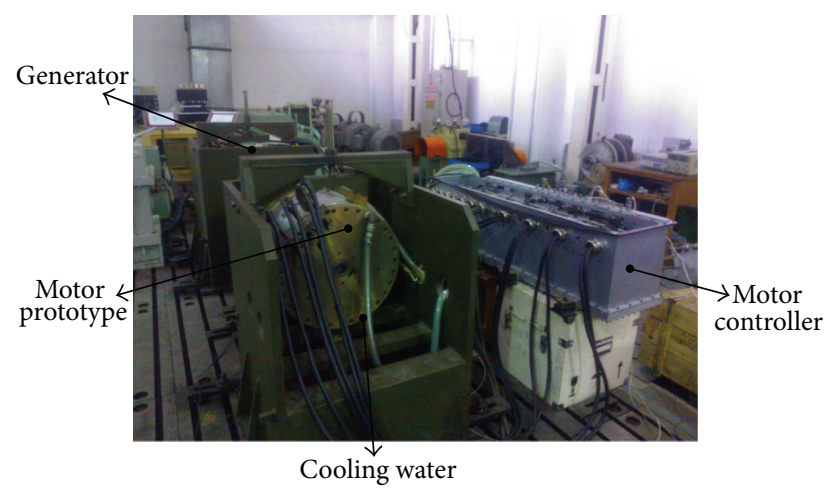

FIgURE 11: Test bench for the temperature measure.

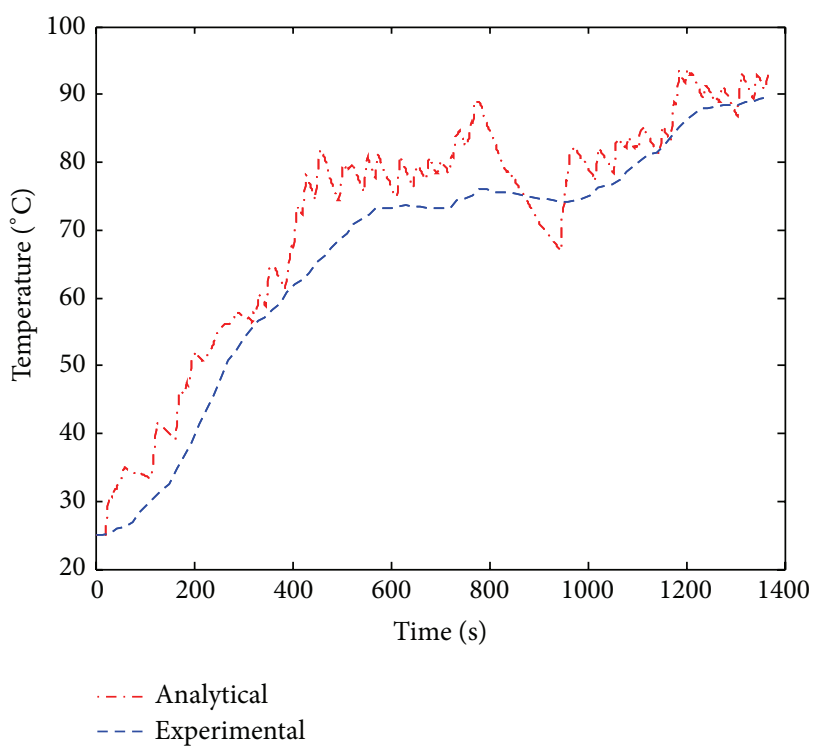

FIGURE 12: Comparison of experimental and analytical temperature distribution of end winding under one driving duty cycle.

rapidly at around $800 \mathrm{~s}$, while the measured temperature remains unchanged. This is caused by time delay of mechanical coupling devices, and this is a drawback of using lumped parameter thermal model. The rest of error component can be attributed to the following issues: (a) simplifications and assumptions used in analysis, (b) loss estimation error comparing to real operating condition, and (c) unknown material thermal property data.

\section{Conclusion}

A lumped parameter thermal model is used to study the thermal behavior of a surface-mounted brushless AC PM machine for electrical vehicle application under the UDDS driving duty cycle. The equivalent thermal parameter of winding is calculated and introduced into the thermal model. The FEA based iron loss, PM loss, and copper loss scaling techniques are utilized to obtain the loss distribution under the duty cycle in a timely manner. The test bench for temperature measurement has been set up to validate the proposed analysis method. And the agreement between analysis and experimental results shows this method is convincing.

\section{Conflict of Interests}

The authors declare that there is no conflict of interests regarding the publication of this paper.

\section{References}

[1] X. Hu, N. Murgovski, L. M. Johannesson, and B. Egardt, "Comparison of three electrochemical energy buffers applied to a hybrid bus powertrain with simultaneous optimal sizing and energy management," IEEE Transactions on Intelligent Transportation Systems, vol. 15, no. 3, pp. 1193-1205, 2014.

[2] X. Hu, N. Murgovski, L. Johannesson, and B. Egardt, "Energy efficiency analysis of a series plug-in hybrid electric bus with different energy management strategies and battery sizes," Applied Energy, vol. 111, pp. 1001-1009, 2013.

[3] X. Hu, L. Johannesson, N. Murgovski, and B. Egardt, "Longevity-conscious dimensioning and power management of the hybrid energy storage system in a fuel cell hybrid electric bus," Applied Energy, vol. 137, pp. 913-924, 2015.

[4] J. Fan, C. Zhang, Z. Wang et al., "Thermal analysis of permanent magnet motor for the electric vehicle application considering driving duty cycle," IEEE Transactions on Magnetics, vol. 46, no. 6, pp. 2493-2496, 2010.

[5] K. Chau and W. Li, "Overview of electric machines for electric and hybrid vehicles," International Journal of Vehicle Design, vol. 64, no. 1, pp. 46-71, 2014.

[6] J. Pries and H. Hofmann, "Magnetic and thermal scaling of electric machines," International Journal of Vehicle Design, vol. 61, no. 1-4, pp. 219-232, 2013.

[7] R. Wrobel, G. Vainel, C. Copeland, T. Duda, D. Staton, and P. Mellor, "Investigation of mechanical loss and heat transfer in an axial-flux PM machine," in Proceedings of the 5th Annual IEEE Energy Conversion Congress and Exhibition (ECCE '13), pp. 4372-4379, September 2013.

[8] D. A. Howey, A. S. Holmes, and K. R. Pullen, "Measurement and CFD prediction of heat transfer in air-cooled disc-type electrical machines," IEEE Transactions on Industry Applications, vol. 47, no. 4, pp. 1716-1723, 2011.

[9] D. A. Howey, A. S. Holmes, and K. R. Pullen, "Measurement of stator heat transfer in air-cooled axial flux permanent magnet machines," in Proceedings of the 35th Annual Conference of the IEEE Industrial Electronics Society (IECON '09), pp. 1197-1202, November 2009.

[10] A. C. Malloy, R. F. Martinez-Botas, M. Jaensch, and M. Lamperth, "Measurement of heat generation rate in the permanent magnets of rotating electrical machines," in Proceedings of the 6th IET International Conference on Power Electronics, Machines and Drives (PEMD '12), pp. 1-6, March 2012.

[11] C. P. Steinmetz, "On the law of hysteresis (originally published in 1892)," Proceedings of the IEEE, vol. 72, no. 2, pp. 196-221, 1984.

[12] G. Bertotti, "General properties of power losses in soft ferromagnetic materials," IEEE Transactions on Magnetics, vol. 24, no. 1, pp. 621-630, 1988.

[13] K. W. E. Cheng and P. D. Evans, "Calculation of winding losses in high-frequency toroidal inductors using single strand 
conductors," IEE Proceedings: Electric Power Applications, vol. 141, no. 2, pp. 52-62, 1994.

[14] J. Acero, R. Alonso, J. M. Burdío, L. A. Barragán, and D. Puyal, "Frequency-dependent resistance in Litz-wire planar windings for domestic induction heating appliances," IEEE Transactions on Power Electronics, vol. 21, no. 4, pp. 856-866, 2006.

[15] A.-T. Phung, G. Meunier, O. Chadebec, X. Margueron, and J.-P. Keradec, "High-frequency proximity losses determination for rectangular cross-section conductors," IEEE Transactions on Magnetics, vol. 43, no. 4, pp. 1213-1216, 2007.

[16] K. Atallah, D. Howe, P. H. Mellor, and D. A. Stone, "Rotor loss in permanent-magnet brushless AC machines," IEEE Transactions on Industry Applications, vol. 36, no. 6, pp. 1612-1618, 2000.

[17] L. J. Wu, Z. Q. Zhu, D. Staton, M. Popescu, and D. Hawkins, "Analytical modelling and analysis of open-circuit PM power loss in surface-mounted permanent magnet machines," IEEE Transactions on Magnetics, vol. 48, no. 3, pp. 1234-1246, 2011.

[18] G. L. Skibinski, B. G. Schram, J. R. Brauer, and Z. Badics, "Finite element prediction of losses and temperatures of laminated composite inductors for AC drives," in Proceedings of the IEEE International Electric Machines and Drives Conference (IEMDC '03), pp. 756-763, June 2003.

[19] Y. Kawase, T. Ota, and H. Fukunaga, "3-D eddy current analysis in permanent magnet of interior permanent magnet motors," IEEE Transactions on Magnetics, vol. 36, no. 4, pp. 1863-1866, 2000.

[20] Z. Kolondzovski, A. Belahcen, and A. Arkkio, "Comparative thermal analysis of different rotor types for a high-speed permanent-magnet electrical machine," IET Electric Power Applications, vol. 3, no. 4, pp. 279-288, 2009.

[21] P. H. Mellor, D. Roberts, and D. R. Turner, "Lumped parameter thermal model for electrical machines of TEFC design," IEE Proceedings B: Electric Power Applications, vol. 138, no. 5, pp. 205-218, 1991.

[22] R. Wrobel, J. Goss, A. Mlot, and P. H. Mellor, "Design considerations of a brushless open-slot radial-flux PM hub motor," IEEE Transactions on Industry Applications, vol. 50, no. 3, pp. 17571767, 2014.

[23] P. H. Mellor, R. Wrobel, and D. Holliday, "A computationally efficient iron loss model for brushless AC machines that caters for rated flux and field weakened operation," in Proceedings of the IEEE International Electric Machines and Drives Conference (IEMDC '09), pp. 490-494, May 2009.

[24] R. Wrobel, D. E. Salt, A. Griffo, N. Simpson, and P. H. Mellor, "Derivation and scaling of AC copper loss in thermal modeling of electrical machines," IEEE Transactions on Industrial Electronics, vol. 61, no. 8, pp. 4412-4420, 2014.

[25] X. Wu, R. Wrobel, P. H. Mellor, and C. Zhang, "A computationally efficient PM power loss derivation for surfacemounted brushless AC PM machines," in Proceedings of the 21st International Conference on Electrical Machines (ICEM '14), pp. 17-23, IEEE, September 2014.

[26] N. Simpson, R. Wrobel, and P. H. Mellor, "Estimation of equivalent thermal parameters of impregnated electrical windings," IEEE Transactions on Industry Applications, vol. 49, no. 6, pp. 2505-2515, 2013.

[27] Z. Hashin, “Theory of fiber reinforced materials," NASA Contractor Report, NASA, Washington, DC, USA, 1972.

[28] E. Behrens, "Thermal conductivities of composite materials," Journal of Composite Materials, vol. 2, no. 1, pp. 2-17, 1968.
[29] J. Donea, "Thermal conductivities based on variational principles," Journal of Composite Materials, vol. 6, no. 2, pp. 262-266, 1972.

[30] R. L. Hamilton and O. K. Crosser, "Thermal conductivity of heterogeneous two-component systems," Industrial and Engineering Chemistry Fundamentals, vol. 1, no. 3, pp. 187-191, 1962.

[31] F. P. Incropera and D. P. DeWitt, Fundamentals of Heat and Mass Transfer, Wiley, New York, NY, USA, 4th edition, 2001. 


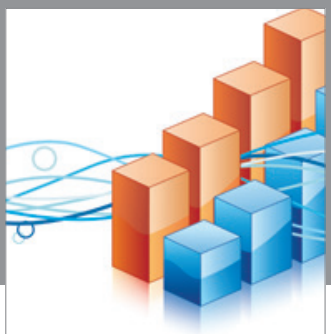

Advances in

Operations Research

vatem alat4

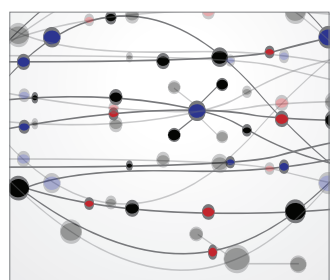

\section{The Scientific} World Journal
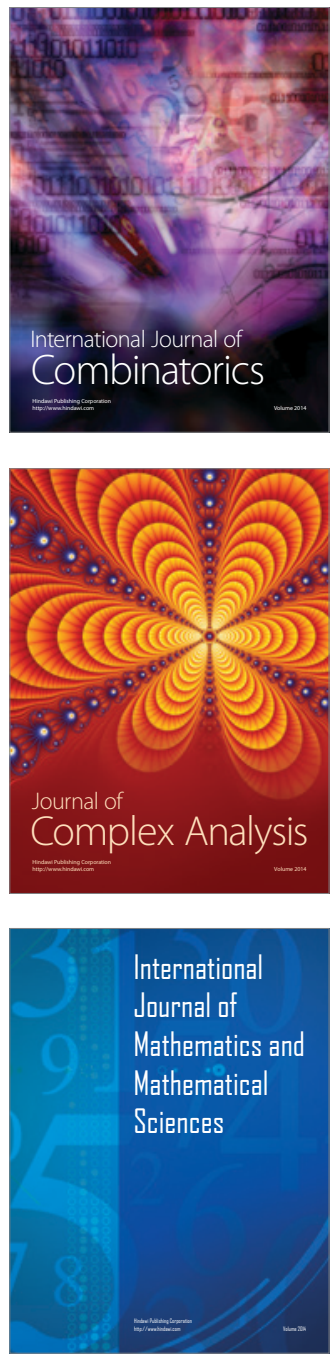
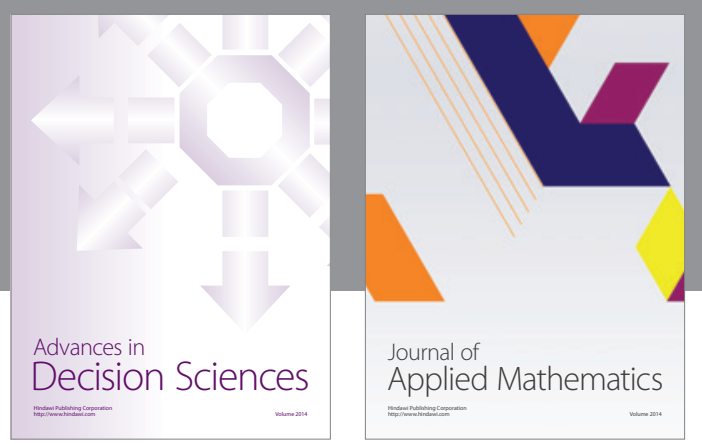

Algebra

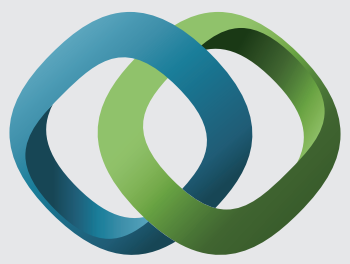

\section{Hindawi}

Submit your manuscripts at

http://www.hindawi.com
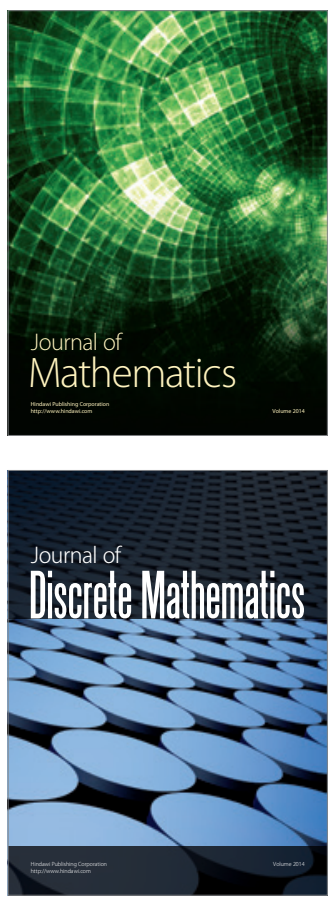

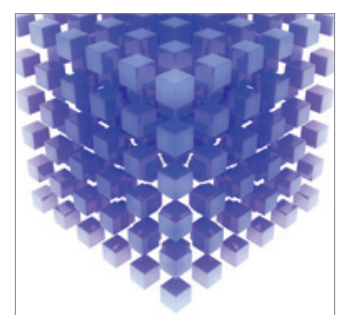

Mathematical Problems in Engineering
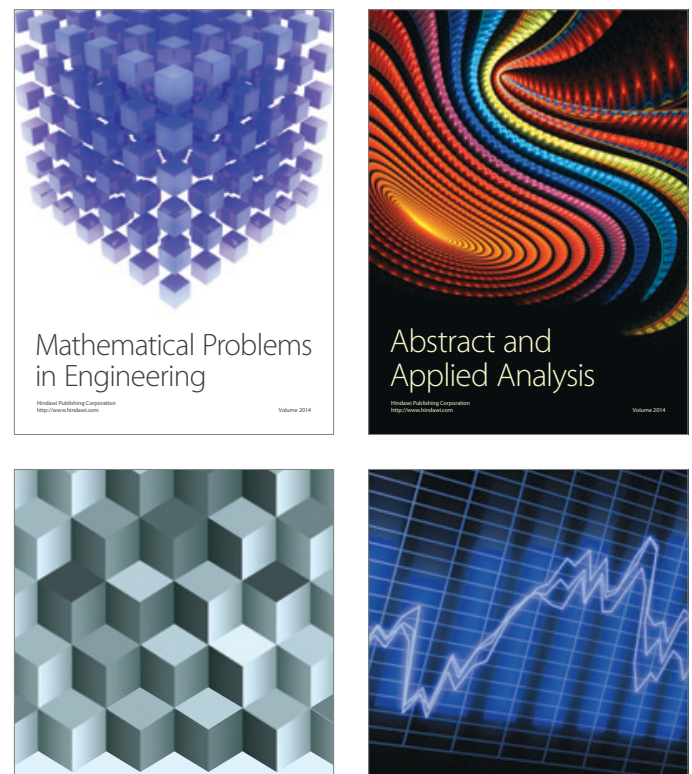

Journal of

Function Spaces

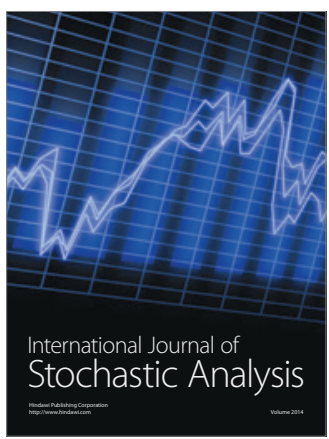

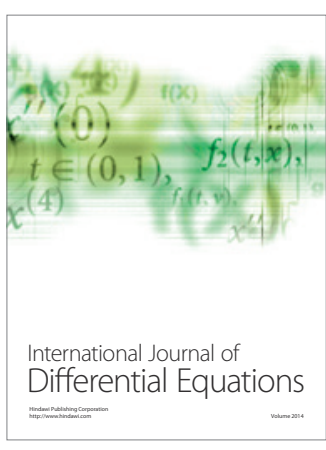
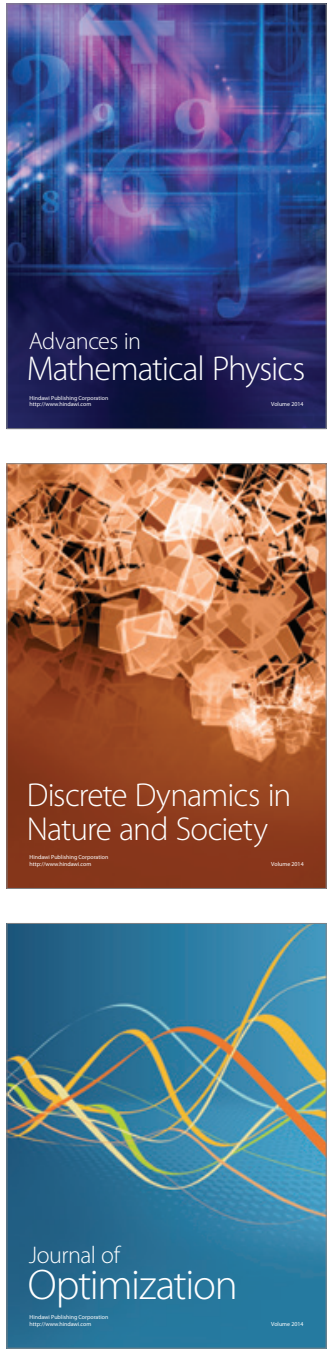